This is an electronic reprint of the original article. This reprint may differ from the original in pagination and typographic detail.

Author(s): Eronen, Johanna; von Bonsdorff, Mikaela; Rantakokko, Merja; Portegijs, Erja; Viljanen, Anne; Rantanen, Taina

Title: $\quad$ Socioeconomic Status and Life-Space Mobility in Old Age

Year: $\quad 2016$

Version:

Please cite the original version:

Eronen, J., von Bonsdorff, M., Rantakokko, M., Portegijs, E., Viljanen, A., \& Rantanen, T. (2016). Socioeconomic Status and Life-Space Mobility in Old Age. Journal of Aging and Physical Activity, 24(4), 617-623. https://doi.org/10.1123/japa.2015-0196

All material supplied via JYX is protected by copyright and other intellectual property rights, and duplication or sale of all or part of any of the repository collections is not permitted, except that material may be duplicated by you for your research use or educational purposes in electronic or print form. You must obtain permission for any other use. Electronic or print copies may not be offered, whether for sale or otherwise to anyone who is not an authorised user. 


\section{Socioeconomic status and life-space mobility in old age}

Johanna Eronen ${ }^{\mathrm{a}}, \mathrm{PhD}$, Mikaela von Bonsdorff ${ }^{\mathrm{a}, \mathrm{b}}, \mathrm{PhD}$, Merja Rantakokko ${ }^{\mathrm{a}}, \mathrm{PhD}$, Erja Portegijs ${ }^{\mathrm{a}}$, $\mathrm{PhD}$, Anne Viljanen ${ }^{\mathrm{a}}$, PhD, Taina Rantanen ${ }^{\mathrm{a}}, \mathrm{PhD}$

${ }^{\mathrm{a}}$ Gerontology Research Center and Department of Health Sciences, University of Jyväskylä

${ }^{\mathrm{b}}$ Folkhälsan Reseach Center, Helsinki, Finland

Running head: SES and life-space mobility

Corresponding author:

Johanna Eronen

Mailing address: Gerontology Research Center and Department of Health Sciences, University of Jyväskylä, P.O. Box 35 (Viv), 40014 University of Jyväskylä, Finland

Telephone +35840805 3550, Fax +358 142602001

E-mail: johanna.eronen@jyu.fi

Author note:

This work was supported by the Ministry of Education and Culture in Finland and the Academy of Finland, the Future of Living and Housing (ASU-LIVE) program. In addition, The Academy of Finland supported MBvB (personal grant no. 257239), MR (personal grant no. 285747) and AV (personal grant no. 251723). The funding agencies played no role in the design, conduct, data management, analysis or manuscript preparation related to this article. Michael Freeman is acknowledged for proof-reading the article. The authors declare no conflicts of interest. 


\begin{abstract}
Objectives. Life-space mobility describes the extent of community mobility of older persons. The aim of this cross-sectional study was to examine the relationship between socioeconomic status (SES) and life-space mobility and to investigate whether associations might be explained by SES-related disparities in health and functioning. Methods. The participants ( $\mathrm{n}=848)$ were community-dwelling, aged 75-90. Education and occupation were used to indicate SES. Life-Space Assessment (range 0-120) was used to indicate distance and frequency of moving and assistance needed in moving. Results. People with low education had lower life-space mobility scores than those with intermediate or high education: marginal means 63.5, 64.8 and $70.0(p=0.003)$, respectively. SES-related health disparities, i.e. higher body mass index, poorer cognitive capacity and poorer physical performance explained the association, rendering it non-significant (marginal means 65.2, 65.3 and 67.5, p=0.390). Discussion. Low SES and restricted life space mobility often coexist with overweight, reduced cognition, and poorer physical performance.
\end{abstract}

Keywords: Aging; mobility; socioeconomic status; life-space 


\section{Introduction}

Mobility, defined as the person's ability to go where, when and how one wants to go (Satariano et al., 2012) is a concept which describes movement in its broadest sense, including walking, driving and using public or other forms of transportation. Life-space mobility is a practical method to get an overall picture of how an older person is able to function in daily life in his or her environment, including such aspects as how, where and when the person moves around in his or her environment (Allman, Sawyer, \& Roseman, 2006).

Life-space mobility refers to the spatial area through which a person purposely moves in daily life, taking into account how often the person is mobile in the area and also the potential need of assistance for doing so (Baker, Bodner, \& Allman, 2003). It reflects the balance between the person's physiologic capacity and the features of the environment, which may either support or restrict a person's mobility, and consequently participation in society. Life-space mobility thus represents the concrete activity of a person in his/her daily life and it includes all forms of mobility, from walking in one's home, taking a bus to a market or driving to another town to visit a friend. At its most restricted a person's life-space can be comprised of his or her bed or bedroom and when completely unrestricted it can extend to areas outside the town one lives in and even abroad.

Life-space mobility correlates with physical activity: unrestricted life-space has been associated with higher objectively measured physical activity (Tsai et al., 2015) and restricted life-space mobility with low physical activity (Portegijs, Tsai, Rantanen, \& Rantakokko, 2015). Unrestricted life-space mobility also correlates positively with quality of life (Rantakokko, Portegijs, Viljanen, Iwarsson, \& Rantanen, 2013) and active social participation (Barnes et al., 2007). Restricted life-space has been, in turn, associated with several other negative health- 
related factors: poor physical performance, a reduced sense of autonomy (Portegijs, Rantakokko, Mikkola, Viljanen, \& Rantanen, 2014), depressive symptoms (Polku et al., 2015), declined cognition (James, Boyle, Buchman, Barnes, \& Bennett, 2011), and frailty (Xue, Fried, Glass, Laffan, \& Chaves, 2008).

Many of the factors associated with restricted life-space are similar to those observed in the association between socioeconomic status (SES) and health and functioning: low SES correlates with walking difficulties (Groffen et al., 2013; Koster et al., 2005; Melzer, Izmirlian, Leveille, \& Guralnik, 2001), poor physical functioning (Enroth, Raitanen, Hervonen, \& Jylhä, 2013) and cognitive difficulties (Atti et al., 2010; Karp et al., 2004). Socioeconomic disparities, meaning differences in health and functioning which are associated with educational attainment or other socioeconomic measures (Adler \& Newman, 2002) have been widely documented in earlier studies. Socioeconomic status has repeatedly been shown to be a major contributor to inequalities in health (Marmot \& Bell 2012, Shavers 2007) and it also contributes to older people's opportunities to be physically active (Eronen, von Bonsdorff, Rantakokko, \& Rantanen, 2012) and the actual physical activity levels (Hillsdon, Lawlor, Ebrahim, \& Morris, 2008; Tucker-Seeley, Subramanian, Li, \& Sorensen, 2009).

To the authors' knowledge no studies thus far have specifically addressed socioeconomic disparities in life-space mobility. Earlier studies among older Mexican Americans (Al Snih et al., 2012), older people living in Colombia and Brazil (Curcio et al., 2013) and older people living in the US, both white and African-American, (Allman et al., 2006; Peel et al., 2005), suggest that indicators of socioeconomic status and life-space mobility correlate. We hypothesized that socioeconomic status is associated with life-space mobility and that SES-related disparities in health and functioning underlie the association. Thus, the aim of this study was to investigate the 
association between socioeconomic status and life-space mobility and to investigate whether the potential association found might be explained by SES-related disparities in health and functioning.

\section{Material and methods}

Data and Participants. The data for this study form a part of the Life-Space Mobility in Old Age project, which is a cohort study of individual and environmental factors underlying the life-space mobility of community-dwelling older people in Finland. The study methodology has been described elsewhere (Rantanen et al., 2012). We present cross-sectional analyses of the baseline data. We recruited participants from a random sample of 2550 people, aged 75-90 years and living in the Finnish municipalities of Jyväskylä and Muurame, whose personal details were drawn from the population register. Using a representative sample as a starting point for recruitment alleviates bias common in non-probability sampling. The size of the recruitment area was 1660 square kilometers and it included urban, suburban and rural areas. The total population of the area was 146500 and the population in the study age range was 8914 . The potential participants were contacted by a letter and over the phone to enquire about their willingness and assess their suitability to take part in the study. Of them, 2269 were reached by telephone. 1111 of those reached were not interested in participating in a study and 304 did not meet the eligibility criteria (community-dwelling in the study area and able to communicate). Altogether 854 persons were interviewed in their homes by trained interviewers during spring 2012. During the home interviews, four participants were excluded due to communication problems and for two persons the data were lost, hence the final baseline sample size was 848 persons. Nonresponse analyses showed that those who declined to participate were older, had poorer self-rated 
health and that they went less often outdoors than those who participated in the study (Rantanen et al., 2012). Even though the study sample represents a slightly healthier section of this agegroup, there is still great variability supporting the validity of the association. The project was approved by the Ethical Committee of the University of Jyväskylä and the study was conducted in compliance with the principles of the Helsinki Declaration. All participants signed an informed consent.

Life-space mobility. Life-space mobility was assessed using the 15-item University of Alabama at Birmingham Study of Aging Life-Space Assessment (LSA) (Baker et al., 2003) which was translated into Finnish. For each life-space level (bedroom, other rooms, outside home, neighborhood, town, beyond town), participants were asked how many days per week they had attained that level during the past 4 weeks and whether they had needed help from another person or from assistive devices. The life-space mobility score (range 0-120), indicating distance, frequency and level of independence, was used in this study as the outcome variable. Higher scores indicate better life-space mobility. For the descriptive analyses, the life-space score was dichotomized into restricted life-space (scores 0-59) and unrestricted life-space (scores 60-120) (Sawyer \& Allman, 2010). The cut-off score 60 is based on previous studies on lifespace mobility, which have shown that the score of 60 or above corresponds well with the persons' ability to independently reach areas beyond neighborhood level (Sawyer \& Allman, 2010). The reproducibility of the LSA was found to be fairly good in this population-based sample (Portegijs, Iwarsson, Rantakokko, Viljanen, \& Rantanen, 2014).

Education. The highest educational attainment was assessed with the question "What is the highest level of education you have attained?" with nine response options: 1) Less than primary school, 2) Primary school, 3) Primary school and at least one year of vocational 
education, 4) Middle school or folk high school, 5) Middle school or folk high school and at least one year of vocational education, 6) High school, 7) High school and at least one year of vocational education, 8) University degree and 9) Other education. For the analyses, the level of education was categorized into three groups: low education (1-2), intermediate education (3-5) and high education (6-8) (Enroth et al., 2013; Sainio, Martelin, Koskinen, \& Heliövaara, 2007). This categorization is based on the Finnish school system as it was at the time when the participants went to school: 6 years of primary school was compulsory for all children aged 7 to 13; some then continued in secondary and/or vocational schools, while a small proportion graduated from upper secondary school and continued to university studies (Statistics Finland, 2007). All of those who had selected "Other education" in the questionnaire had also described this, and thus it was used to define their level of education. Information on level of education was available for 847 persons.

Occupation. The longest held occupation during the participant's working years was elicited with an open-ended question and the resulting occupations were encoded according to the Classification of Occupations 2010 by Statistics Finland (2011), which is based on the International Standard Classification of Occupations ISCO-08 by the International Labour Organization (ILO). Occupational status was classified into three hierarchical groups: manual (eg. farmers, plumbers and cleaners), lower non-manuals (eg. nurses, bank clerks and traders) and upper non-manuals (eg. teachers, managers and dentists). Information on occupation was available for all our participants and it is worth noting that at the time when the participants in this study were in working age, the employment rate for women was high in Finland (Statistics Finland, 1958; Enroth et al., 2013). Twelve persons (1.4\%) had reported that they had been 
housewives and consequently were not included in any of the occupational groups. Thus, in the analyses in which occupation is a variable the number of participants is 836 .

Covariates. Age and gender were drawn from the population register. Living status (alone/with someone) was self-reported on a questionnaire. Information on physician-diagnosed chronic conditions was collected by self-report using a list of 22 chronic conditions (Rantanen et al., 2012). Body mass index was calculated as self-reported weight in kilograms (kg) divided by height in meters (m) squared. Cognitive status and depressive symptoms were assessed using screening tools: the Mini-Mental State Examination (MMSE) (Folstein, Folstein, \& McHugh, 1975) to assess cognition and the Center for Epidemiologic Studies Depression Scale (CES-D) (Radloff, 1977) to assess depressive symptoms. Lower limb physical functioning was assessed with the Short Physical Performance Battery (SPPB) (Guralnik et al., 1994). The SPPB battery includes three tests which assess balance, walking speed and the ability to rise from a chair. The SPPB score ranges from 0 to 12 , higher scores indicating better lower extremity functioning.

Statistical analyses. The analyses were started off by choosing the indicators of health and functioning potentially explaining the association between SES and life-space mobility. The indicators were chosen according to three criteria: first, they had previously been found to be associated with mobility in general (Melzer et al., 2001; Rautio, Adamson, Heikkinen, \& Ebrahim, 2006; Sainio et al., 2007); second, they would be associated with the predictor (education or occupation), and third, they would be associated with the outcome of this study (life-space mobility).

Differences in background characteristics and the chosen indicators of health and functioning between participants in the restricted and unrestricted life-space mobility groups and in the different SES categories were tested with Kruskall-Wallis and Chi square tests. All 
indicators of health and functioning included in the analyses were associated with life-space mobility: however only cognitive capacity (MMSE score), body-mass index (BMI) and physical functioning (SPPB) were associated also with education and occupation and thus posited as potential explanatory variables in the further analyses.

The association between SES and life-space mobility was investigated with general linear model. As the association between SES and life-space mobility did not differ between men and women, the data on both sexes were combined. The base model included age and was adjusted for gender. Each explanatory variable was then added into the model separately, and finally all the factors were included in the model simultaneously. We present the marginal means of lifespace mobility scores by education and regression coefficients with $95 \%$ Confidence Intervals (CI). All analyses were performed using IBM SPSS Statistics for Windows, Version 22.0 (Armonk, NY: IBM Corp).

\section{Results}

Table 1 shows the differences in the background characteristics and in the indicators of health and functioning between participants with restricted and unrestricted life-space mobility and between educational and occupational groups. The mean age of all participants $(n=848)$ was $80.1( \pm \mathrm{SD} 4.3)$ years and 62 percent were women. Life-space mobility was restricted to the neighborhood level or lower among $28.5 \%$ of the participants. Level of education was low for $38.0 \%$, intermediate for $46.4 \%$ and high for $15.6 \%$ of the participants. The longest held occupation during working age had been manual among 37.9\%, lower non-manual among 43.5\% and upper non-manual among $17.5 \%$ of the participants. Participants in the low education category were older, had higher BMI, poorer cognitive capacity and poorer physical functioning 
than those in the high education category. Similar differences were found between the occupational groups. Among all the participants, men on average had higher LSA scores than women (71.1 vs. $59.5, \mathrm{p}<0.001)$.

In the general linear model, the results were parallel for education and occupation, and therefore we only present the marginal means and regression coefficients of life-space mobility scores by education in Table 2 . The marginal means yielded by the age- and gender-adjusted base model showed that the high-educated participants had higher life-space mobility scores, indicating higher life-space mobility, compared to those with intermediate and low education: marginal means 70.0 (SE 1.6) for high, 64.8 (SE 0.9) for intermediate and 63.5 (SE 1.0) for low education. When the covariates were added one by one into the base model the associations weakened. The strongest individual covariates were SPPB and MMSE scores, which markedly attenuated the association between education and life-space mobility: the regression coefficients in the model with MMSE were -4.31 (95\% Confidence Interval (CI) $-7.97,-0.66)$ for intermediate education and -4.23 (95\% CI $-8.17,-0.28)$ for low education, and in the model with SPPB -3.20 (95\% CI -6.40, 0.005) for intermediate education and $-4.03(95 \% \mathrm{CI}-7.35,-0.71)$ for low education. In the model which included BMI the regression coefficients were -3.93 (95\% CI $-7.54,-0.31)$ for intermediate education and $-4.93(95 \%$ CI $-8.69,-1.18)$ for low education. When all indicators of health and functioning (MMSE, BMI, SPPB) were added into the models, the association between education and life-space mobility were considerably attenuated and no longer statistically significant.

\section{Discussion}


A socioeconomic gradient in life-space mobility was found as hypothesized: people with high educational attainment had higher life-space mobility scores than people with lower education. The observed differences in life-space mobility score means were moderate, probably due to the fact that the majority of the participants were rather well-functioning. A difference of 10 points in life-space mobility scores is considered to be clinically significant (Baker et al., 2003), however also relatively small differences can be meaningful in older persons' daily lives. For example a decrease of 1.5-2.5 points over one year has been associated with decline in selfreported health and mobility (Portegijs et al., 2014). Our results showed that the observed association between education and life-space mobility was largely explained by the objectively measured indicators of health and functioning associated with SES disparities: people with low education were more likely to have higher BMI, poorer cognitive capacity and poorer physical performance than participants with higher educational attainment. As life-space mobility describes a person's actual community mobility and thereby access to community amenities, the current results are in line with earlier studies, which have shown that people with low SES more often report less opportunities for physical activity than people with high SES (Eronen et al., 2012) and that physical activity is less common among people with restricted life-space mobility than among people with unrestricted life-space mobility (Tsai et al., 2015).

Owing to the cross-sectional design of the study we were only able to confirm that low SES and restricted life space mobility often coexist with overweight, reduced cognition, and poorer lower extremity functioning. Determining the temporal order of these was not, of course, possible. We would speculate that underlying the association found here between SES and lifespace mobility there may be a causal chain, which can be summarized as follows: During their life-course people with low SES may have been exposed to cumulative risk factors and deprived 
conditions, that have propelled health decline such as high BMI, cognitive difficulties and problems in lower-limb functioning, which, in turn have led to lower life-space mobility in old age. Restricted life-space mobility and low physical activity can further impair the functioning of older people with low SES. Conversely, older people with high SES are more likely to possess resources, such as money, equipment or knowledge which may help them to maintain mobility on the more distant levels of life-space (Link \& Phelan, 1995; Willson, Shuey, \& Elder Jr., 2007). Larger life-space may in turn provide them with better opportunities to participate in various social and physical activities (Portegijs et al., 2015) and help to preserve cognitive capacity (Crowe et al., 2008). Our causality hypothesis is line with the social causation model, which presumes that socioeconomic position is a determinant of health and diseases. However the possibility of reverse causality should not be ignored. It is also conceivable that an adverse health outcome or illness can have a downward effect on socioeconomic position, as posited by the social selection theory (Dohrenwend et al., 1992). In this case, however, we believe that it is more likely that education, which is achieved early in life, modifies the functioning of an individual, rather than life-space mobility modifying education (Alwin \& Wray, 2005).

Socioeconomic differences in health and health behavior prevail in the Finnish population, including the oldest age groups (Enroth et al., 2013; Talala et al., 2014). Health differences are considered to arise fundamentally from living and working conditions (Marmot, Allen, Bell, Bloomer, \& Goldblatt, 2012). Living and working conditions influence health behaviors, such as smoking, alcohol use, vegetable consumption and physical activity, which are in turn associated with health differences and explain the association between SES and different health outcomes (Laaksonen et al., 2008). For example high BMI has been shown to explain the association between low SES and mobility difficulties, especially in women (Sainio et al., 2007). 
Our observation of the association between SES and life-space mobility adds novel information about the potential mechanism linking socioeconomic position with older persons' opportunities to be active in their environments. Somewhat unexpectedly, however, the number of chronic conditions did not vary between the SES groups in this study. Previous studies have shown conflicting results on the mediating effect of chronic conditions on the association of SES and overall mobility: for example, in a Swedish study chronic conditions explained only a small part of the association (Welmer, Kareholt, Rydwik, Angleman, \& Wang, 2013) while in a Finnish study a stronger association was observed (Sainio et al., 2007). The discrepancies in these results may be due to different ways evaluating chronic conditions.

Health differences aside, there might be other explanations for the association between SES and life-space mobility that were not addressed in this study. The role of perceived environmental barriers in restricted life-space mobility was demonstrated in a recent study (Rantakokko, Iwarsson, Portegijs, Viljanen, \& Rantanen, 2014). This finding is understandable, as people who perceive areas in their environment as challenging tend to avoid moving around in those areas (Hovbrandt, Fridlund, \& Carlsson, 2007). However, the socioeconomic status of the participants in this study did not correlate with perceived environmental barriers in the further analyses. Another possible explanation may be related to previous findings that, in addition to individual SES, area SES has shown distinct effects on older people's walking activity (Cerin et al., 2013). Neighborhood or area SES is known to be associated with difficulties in walking and climbing stairs (Lang, Llewellyn, Langa, Wallace, \& Melzer, 2008), quality of life (Breeze et al., 2005), chronic conditions (Chaikiat, Li, Bennet, \& Sundquist, 2012) and reduced physical activity (Amuzu, Carson, Watt, Lawlor, \& Ebrahim, 2009; Hillsdon et al., 2008). It is possible, therefore, that those with low SES were living in more disadvantaged neighborhoods than those 
with high SES and that this was reflected in the association between individual SES and lifespace mobility. Unfortunately we were not able to take into account the socioeconomic status of the neighborhood in which the participants resided.

For many older people in Finland, walking is the main way of getting around and it is a prerequisite for using other forms of transportation as well. Restricted life-space mobility thus restricts older persons' autonomy by limiting their opportunities of being able to go where, when and how one wants. Life-space mobility, especially when restricted to areas close to one's home, can be highly dependent on the possibilities to arrange assistance for getting to places where one wants to go. People whose life-space is unrestricted have more freedom in mobility and they are more independent in making choices in their everyday lives. Restricted life-space mobility could be alleviated by offering assistance in going outdoors to those who need it - regardless of their socioeconomic status. Help and assistance in daily activities is often put into practice by bringing services, e.g. meals, to older persons' homes, yet then the opportunity for physical activity is missed.

Strengths and limitations. This was the first study to specifically address socioeconomic differences in life-space mobility among older people. The main strength of this study was its large population-based sample with very little missing information. The high number of participants allowed us to categorize persons based on their education and occupation into three distinct categories with a sufficient number of participants in each of them to perform the analyses. Moreover, the quality of the data was good: computer-assisted personal interviews were carried out in the participants' homes by trained interviewers. Conducting the interviews in the participants' homes allowed also persons with poorer health to participate in the study. 
Some limitations need to be considered. The participants in this study were rather wellfunctioning, which means that the range in life-space mobility in the study sample may be smaller than in the general population. Therefore the strength of the association of SES and lifespace mobility may be underestimated. We used self-reports of weight, height and physiciandiagnosed chronic conditions, which are not as accurate as they would have been if they had been measured or confirmed by a physician in a clinical examination. It should also be acknowledged that in some cases there might have been difficulties in defining neighborhood and town areas fully in accordance with the life-space mobility assessment (Portegijs et al., 2014). However, the interviewers were able to guide the participants in defining these areas and hence we do not believe that this will have introduced error into our results. Another limitation is the cross-sectional design of this study, which makes it impossible to estimate how stable lifespace mobility has been during recent years or months, and renders purely hypothetical any interpretations or conclusions regarding causality.

Conclusion. This study demonstrated an association between socioeconomic status and life-space mobility in old age. Higher BMI, poorer cognitive capacity and poorer physical performance among the participants with low SES explained the observed association. It is possible, therefore, that people with low SES may have fewer opportunities for using community amenities and participating in meaningful activities outside the home. In future studies on lifespace mobility, the role of area SES should be taken into account. 


\section{References}

Adler, N. E., \& Newman, K. (2002). Socioeconomic disparities in health: pathways and policies. Health Affairs (Project Hope), 21(2), 60-76.

Al Snih, S., Peek, K. M., Sawyer, P., Markides, K. S., Allman, R. M., \& Ottenbacher, K. J. (2012). Life-Space Mobility in Mexican Americans Aged 75 and Older. Journal of the American Geriatrics Society, 60(3), 532-537. doi:10.1111/j.1532-5415.2011.03822.x

Allman, R. M., Sawyer, P., \& Roseman, J. M. (2006). The UAB Study of Aging: background and insights into life-space mobility among older Americans in rural and urban settings. Aging Health, 2(3), 417-429. doi:doi: 10.2217/1745509X.2.3.417

Alwin, D. F., \& Wray, L. A. (2005). A Life-Span Developmental Perspective on Social Status and Health. The Journals of Gerontology Series B: Psychological Sciences and Social Sciences, 60(Special Issue 2), S7-S14. doi:10.1093/geronb/60.Special_Issue_2.S7

Amuzu, A., Carson, C., Watt, H. C., Lawlor, D. A., \& Ebrahim, S. (2009). Influence of area and individual lifecourse deprivation on health behaviours: findings from the British Women's Heart and Health Study. European Journal of Cardiovascular Prevention \& Rehabilitation, 16(2), 169-173. doi:10.1097/HJR.0b013e328325d64d

Atti, A. R., Forlani, C., De Ronchi, D., Palmer, K., Casadio, P., Dalmonte, E., \& Fratiglioni, L. (2010). Cognitive impairment after age 60: clinical and social correlates in the Faenza Project. Journal of Alzheimer's Disease : JAD, 21(4), 1325-1334. 
Baker, P. S., Bodner, E. V., \& Allman, R. M. (2003). Measuring life-space mobility in community-dwelling older adults. Journal of the American Geriatrics Society, 51(11), 16101614. doi:10.1046/j.1532-5415.2003.51512.x

Barnes, L. L., Wilson, R. S., Bienias, J. L., de Leon, C. F., Kim, H. J., Buchman, A. S., \& Bennett, D. A. (2007). Correlates of life space in a volunteer cohort of older adults. Experimental Aging Research, 33(1), 77-93. doi:10.1080/03610730601006420

Breeze, E., Jones, D. A., Wilkinson, P., Bulpitt, C. J., Grundy, C., Latif, A. M., \& Fletcher, A. E. (2005). Area deprivation, social class, and quality of life among people aged 75 years and over in Britain. International Journal of Epidemiology, 34(2), 276-283. doi:10.1093/ije/dyh328

Cerin, E., Mellecker, R., Macfarlane, D. J., Barnett, A., Cheung, M. C., Sit, C. H., \& Chan, W. M. (2013). Socioeconomic status, neighborhood characteristics, and walking within the neighborhood among older Hong Kong Chinese. Journal of Aging and Health, 25(8), $1425-$ 1444. doi:10.1177/0898264313510034

Chaikiat, A., Li, X., Bennet, L., \& Sundquist, K. (2012). Neighborhood deprivation and inequities in coronary heart disease among patients with diabetes mellitus: a multilevel study of 334,000 patients. Health \& Place, 18(4), 877-882.

doi:10.1016/j.healthplace.2012.03.003

Crowe, M., Andel, R., Wadley, V. G., Okonkwo, O. C., Sawyer, P., \& Allman, R. M. (2008). Life-space and cognitive decline in a community-based sample of African American and 
Caucasian older adults. The Journals of Gerontology.Series A, Biological Sciences and Medical Sciences, 63(11), 1241-1245. doi:http://dx.doi.org/10.1093/gerona/63.11.1241

Curcio, C. L., Alvarado, B. E., Gomez, F., Guerra, R., Guralnik, J., \& Zunzunegui, M. V. (2013). Life-Space Assessment scale to assess mobility: validation in Latin American older women and men. Aging Clinical and Experimental Research, 25(5), 553-560. doi:10.1007/s40520013-0121-y

Dohrenwend, B. P., Levav, I., Shrout, P. E., Schwartz, S., Naveh, G., Link, B. G., . . Stueve, A. (1992). Socioeconomic status and psychiatric disorders: the causation-selection issue. Science (New York, N.Y.), 255(5047), 946-952.

Enroth, L., Raitanen, J., Hervonen, A., \& Jylhä, M. (2013). Do Socioeconomic Health Differences Persist in Nonagenarians? The Journals of Gerontology Series B: Psychological Sciences and Social Sciences, 68(5), 837-847. doi:10.1093/geronb/gbt067

Eronen, J., von Bonsdorff, M. B., Rantakokko, M., \& Rantanen, T. (2012). Accumulation of disparity in physical activity in old age. Aging Clin.Exp.Res., 24, 475-479.

Folstein, M. F., Folstein, S. E., \& McHugh, P. R. (1975). "Mini-mental state". A practical method for grading the cognitive state of patients for the clinician. Journal of Psychiatric Research, 12, 189-198. doi:10.1037/t07757-000

Groffen, D. A., Koster, A., Bosma, H., van den Akker, M., Aspelund, T., Siggeirsdottir, K., . . . Age, Gene/Environment Susceptibility-Reykjavik Study Investigators. (2013). Socioeconomic factors from midlife predict mobility limitation and depressed mood three 
decades later; findings from the AGES-Reykjavik Study. BMC Public Health, 13, 1012458-13-101. doi:10.1186/1471-2458-13-101

Guralnik, J. M., Simonsick, E. M., Ferrucci, L., Glynn, R. J., Berkman, L. F., Blazer, D. G., . . Wallace, R. B. (1994). A Short Physical Performance Battery Assessing Lower Extremity Function: Association With Self-Reported Disability and Prediction of Mortality and Nursing Home Admission. The Journals of Gerontology.Series A, Biological Sciences and Medical Sciences, 49(2), 85-94. doi:10.1093/geronj/49.2.M85

Hillsdon, M., Lawlor, D. A., Ebrahim, S., \& Morris, J. N. (2008). Physical activity in older women: associations with area deprivation and with socioeconomic position over the life course: observations in the British Women's Heart and Health Study. Journal of Epidemiology and Community Health, 62(4), 344-350. doi:10.1136/jech.2006.058610

Hovbrandt, P., Fridlund, B., \& Carlsson, G. (2007). Very old people's experience of occupational performance outside the home: possibilities and limitations. Scandinavian Journal of Occupational Therapy, 14(2), 77-85. doi:10.1080/11038120600773013

IBM Corp. (2013). IBM SPSS Statistics for Windows (Version 22.0. ed.). Armonk, NY: IBM Corp.

James, B. D., Boyle, P. A., Buchman, A. S., Barnes, L. L., \& Bennett, D. A. (2011). Life space and risk of Alzheimer disease, mild cognitive impairment, and cognitive decline in old age. The American Journal of Geriatric Psychiatry : Official Journal of the American Association for Geriatric Psychiatry, 19(11), 961-969. doi:10.1097/JGP.0b013e318211c219 
Karp, A., Kåreholt, I., Qiu, C., Bellander, T., Winblad, B., \& Fratiglioni, L. (2004). Relation of Education and Occupation-based Socioeconomic Status to Incident Alzheimer's Disease. American Journal of Epidemiology, 159(2), 175-183. doi:10.1093/aje/kwh018

Koster, A., Penninx, B. W. J. H., Bosma, H., Kempen, G. I. J. M., Harris, T. B., Newman, A. B., ... Kritchevsky, S. B. (2005). Is There a Biomedical Explanation for Socioeconomic Differences in Incident Mobility Limitation? The Journals of Gerontology Series A: Biological Sciences and Medical Sciences, 60(8), 1022-1027. doi:10.1093/gerona/60.8.1022

Laaksonen, M., Talala, K., Martelin, T., Rahkonen, O., Roos, E., Helakorpi, S., . . Prättälä, R. (2008). Health behaviours as explanations for educational level differences in cardiovascular and all-cause mortality: a follow-up of 60000 men and women over 23 years. The European Journal of Public Health, 18(1), 38-43. doi:10.1093/eurpub/ckm051

Lang, I. A., Llewellyn, D. J., Langa, K. M., Wallace, R. B., \& Melzer, D. (2008). Neighbourhood deprivation and incident mobility disability in older adults. Age and Ageing, 37(4), 403-410. doi:10.1093/ageing/afn092

Link, B. G., \& Phelan, J. (1995). Social Conditions As Fundamental Causes of Disease. Journal of Health and Social Behavior, 35(Extra Issue), 80-94. doi:http://dx.doi.org/10.2307/2626958

Marmot, M., Allen, J., Bell, R., Bloomer, E., \& Goldblatt, P. (2012). WHO European review of social determinants of health and the health divide. The Lancet, 380(9846), 1011-1029. doi:http://dx.doi.org/10.1016/S0140-6736(12)61228-8 
Melzer, D., Izmirlian, G., Leveille, S. G., \& Guralnik, J. M. (2001). Educational differences in the prevalence of mobility disability in old age: the dynamics of incidence, mortality, and recovery. The Journals of Gerontology.Series B, Psychological Sciences and Social Sciences, 56(5), S294-301.

Peel, C., Baker, P. S., Roth, D. L., Brown, C. J., Bodner, E. V., \& Allman, R. M. (2005). Assessing Mobility in Older Adults: The UAB Study of Aging Life-Space Assessment. Physical Therapy, 85(10), 1008-1019. doi:http://ptjournal.apta.org/content/85/10/1008

Polku, H., Mikkola, T. M., Portegijs, E., Rantakokko, M., Kokko, K., Kauppinen, M., .. . Viljanen, A. (2015). Life-space mobility and dimensions of depressive symptoms among community-dwelling older adults. Aging \& Mental Health, 19(9), 781-789. doi:10.1080/13607863.2014.977768

Portegijs, E., Iwarsson, S., Rantakokko, M., Viljanen, A., \& Rantanen, T. (2014). Life-space mobility assessment in older people in Finland; measurement properties in winter and spring. BMC Research Notes, 7(1), 323-0500-7-323. doi:10.1186/1756-0500-7-323

Portegijs, E., Rantakokko, M., Mikkola, T. M., Viljanen, A., \& Rantanen, T. (2014). Association Between Physical Performance and Sense of Autonomy in Outdoor Activities and LifeSpace Mobility in Community-Dwelling Older People. Journal of the American Geriatrics Society, 62(4), 615-621. doi:10.1111/jgs.12763

Portegijs, E., Tsai, L., Rantanen, T., \& Rantakokko, M. (2015). Moving through Life-Space Areas and Objectively Measured Physical Activity of Older People. PLoS ONE, 10(8), e0135308. 
Radloff, L. S. (1977). The CES-D Scale. Applied Psychological Measurement, 1(3), 385-401. doi:10.1177/014662167700100306

Rantakokko, M., Iwarsson, S., Portegijs, E., Viljanen, A., \& Rantanen, T. (2014). Associations Between Environmental Characteristics and Life-Space Mobility in Community-Dwelling Older People. Journal of Aging and Health, doi:10.1177/0898264314555328

Rantakokko, M., Portegijs, E., Viljanen, A., Iwarsson, S., \& Rantanen, T. (2013). Life-Space Mobility and Quality of Life in Community-Dwelling Older People. Journal of the American Geriatrics Society, 61(10), 1830-1832. doi:10.1111/jgs.12473

Rantanen, T., Portegijs, E., Viljanen, A., Eronen, J., Saajanaho, M., Tsai, L. T., . . Rantakokko, M. (2012). Individual and environmental factors underlying life space of older people study protocol and design of a cohort study on life-space mobility in old age (LISPE). BMC Public Health, 12 doi:10.1186/1471-2458-12-1018

Rautio, N., Adamson, J., Heikkinen, E., \& Ebrahim, S. (2006). Associations of socio-economic position and disability among older women in Britain and Jyvaskyla, Finland. Archives of Gerontology and Geriatrics, 42(2), 141-155. doi:10.1016/j.archger.2005.06.005

Sainio, P., Martelin, T., Koskinen, S., \& Heliövaara, M. (2007). Educational differences in mobility: the contribution of physical workload, obesity, smoking and chronic conditions. Journal of Epidemiology and Community Health, 61(5), 401-408. doi:10.1136/jech.2006.048306 
Satariano, W. A., Guralnik, J. M., Jackson, R. J., Marottoli, R. A., Phelan, E. A., \& Prohaska, T. R. (2012). Mobility and aging: new directions for public health action. American Journal of Public Health, 102(8), 1508-1515. doi:10.2105/AJPH.2011.300631

Sawyer, P., \& Allman, R. M. (2010). Resilience in mobility in the context of chronic disease and aging: cross-sectional and prospective findings from the University of Alabama at Birmingham (UAB) Study of Aging. In P. S. Fry, \& C. L. M. Keyes (Eds.), Frontiers of Resilient Aging: Life-strengths and wellness in late life (pp. 310-339). New York: Cambridge University Press.

Statistics Finland. (1958). Population by economic activity, industry, industrial status, occupation and vocational training. . Official Statiatics in Finland. VI Population Statistics C 102. 1950 Population Cencus. Volume IX. English summary (). Helsinki: Valtioneuvoston kirjapaino.

Statistics Finland. (2011). Classification of occupation 2010. Helsinki: Statistics Finland.

Talala, K., Härkänen, T., Martelin, T., Karvonen, S., Mäki-Opas, T., Manderbacka, K., . . . Koskinen, S. (2014). Time trends in educational disparities in health and well-being in the Finnish population from 2000 to 2011 (In Finnish). Suomen Lääkärilehti, 69(36), 21852192.

Tsai, L. -., Portegijs, E., Rantakokko, M., Viljanen, A., Saajanaho, M., Eronen, J., \& Rantanen, T. (2015). The association between objectively measured physical activity and life-space mobility among older people. Scandinavian Journal of Medicine \& Science in Sports, 25(4), e368-e373. doi:10.1111/sms.12337 
Tucker-Seeley, R. D., Subramanian, S. V., Li, Y., \& Sorensen, G. (2009). Neighborhood Safety, Socioeconomic Status, and Physical Activity in Older Adults. American Journal of Preventive Medicine, 37(3), 207-213. doi:http://dx.doi.org/10.1016/j.amepre.2009.06.005

Welmer, A. K., Kareholt, I., Rydwik, E., Angleman, S., \& Wang, H. X. (2013). Educationrelated differences in physical performance after age 60: a cross-sectional study assessing variation by age, gender and occupation. BMC Public Health, 13(1), 641. doi:10.1186/14712458-13-641

Willson, A. E., Shuey, K. M., \& Elder Jr., G. H. (2007). Cumulative Advantage Processes as Mechanisms of Inequality in Life Course Health. American Journal of Sociology, 112(6), 1886-1924. doi:10.1086/512712

Xue, Q. L., Fried, L. P., Glass, T. A., Laffan, A., \& Chaves, P. H. (2008). Life-space constriction, development of frailty, and the competing risk of mortality: the Women's Health And Aging Study I. American Journal of Epidemiology, 167(2), 240-248. doi:10.1093/aje/kwm270 
Table 1. Participant characteristics according to life-space mobility and socioeconomic status.

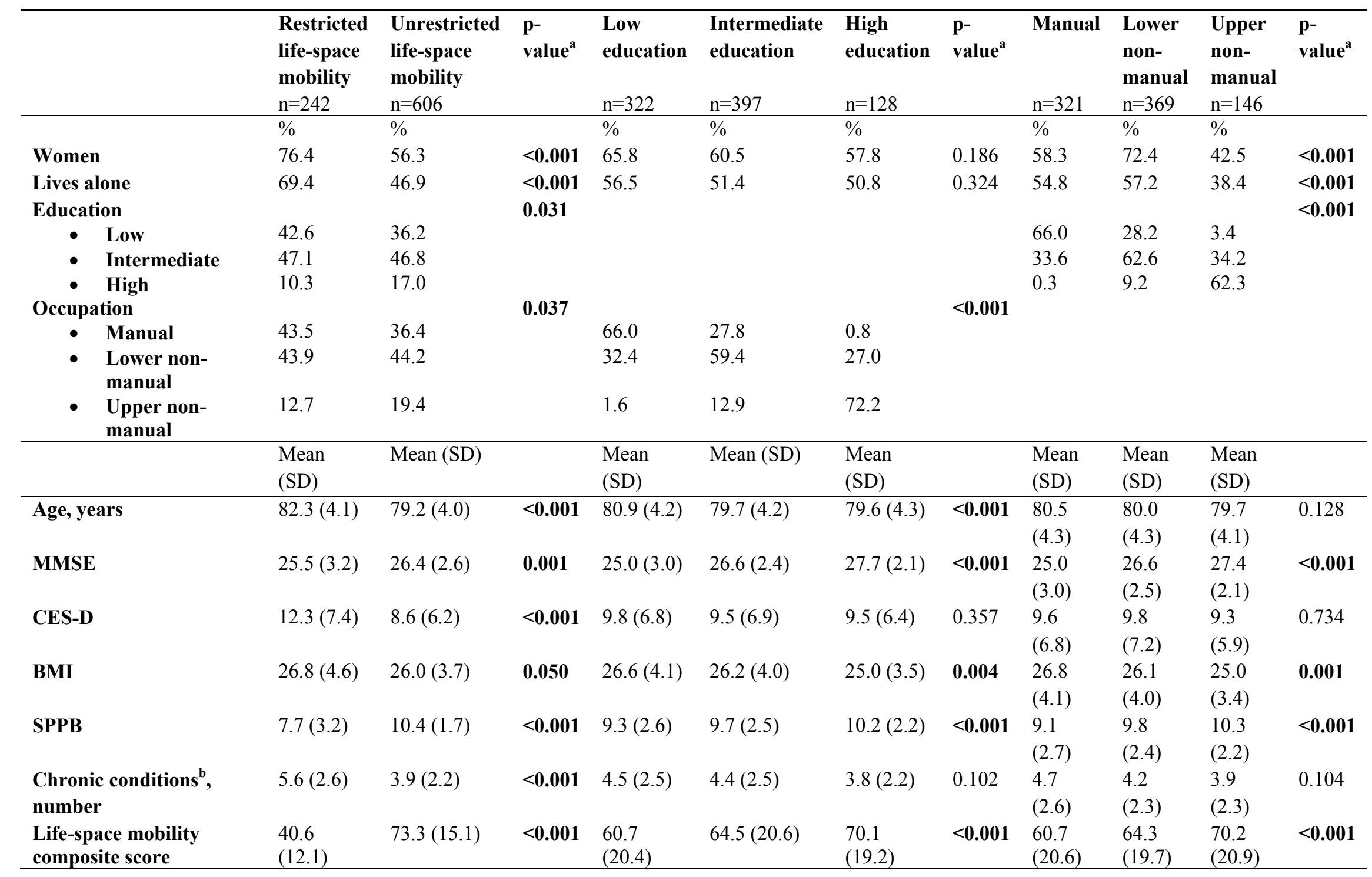


Note. ${ }^{\mathrm{a}}$ p-value, Kruskall-Wallis -test and Chi square test. SD = Standard Deviation; BMI = Body mass index; MMSE = Mini-mental state examination; CES-D = Center for Epidemiologic Studies Depression Scale; SPPB = Short physical performance battery. ${ }^{b}$ Chronic conditions included pulmonary, cardiac, circulatory, locomotor, rheumatic, eye, neurological, endocrinological, gastroenteric and dermatological diseases; hearing disorders, cancers and psychological disorders. 
Table 2. Marginal means (MM) and standard errors (SE) of life-space mobility scores and regression coefficients $(\beta)$ with $95 \%$ Confidence Intervals (CI) by education.

\begin{tabular}{|c|c|c|c|c|c|c|c|c|c|}
\hline & \multicolumn{8}{|c|}{ Education } & \multirow{3}{*}{ p-value } \\
\hline & \multicolumn{2}{|c|}{ High } & \multicolumn{3}{|c|}{ Intermediate } & \multicolumn{3}{|c|}{ Low } & \\
\hline & MM (SE) & B CI & MM (SE) & $\beta$ & CI & MM (SE) & $\beta$ & CI & \\
\hline Unadjusted & $70.1(1.8)$ & ref. & $64.5(1.0)$ & -5.66 & $-9.71,-1.61$ & $60.6(1.1)$ & -9.49 & $-13.66,-5.32$ & $<0.001$ \\
\hline Gender and age & $70.0(1.6)$ & ref. & $64.8(0.9)$ & -5.22 & $-8.86,-1.57$ & $63.5(1.0)$ & -6.45 & $-10.21,-2.68$ & 0.003 \\
\hline +MMSE & $68.7(1.6)$ & ref. & $64.4(0.9)$ & -4.31 & $-7.97,-0.66$ & $64.5(1.1)$ & -4.23 & $-8.17,-0.28$ & 0.058 \\
\hline$+\mathbf{B M I}$ & $69.1(1.6)$ & ref. & $65.2(0.9)$ & -3.93 & $-7.54,-0.31$ & $64.2(1.0)$ & -4.93 & $-8.69,-1.18$ & 0.034 \\
\hline + SPPB & $68.4(1.4)$ & ref. & $65.2(0.8)$ & -3.20 & $-6.40,0.005$ & $64.4(0.9)$ & -4.03 & $-7.35,-0.71$ & 0.056 \\
\hline + MMSE, BMI, SPPB & $67.5(1.6)$ & ref. & $65.3(0.9)$ & -2.13 & $-5.39,1.12$ & $65.2(1.0)$ & -2.28 & $-5.82,1.26$ & 0.390 \\
\hline
\end{tabular}

